\title{
Life quality and empathy in children with celiac disease
}

\author{
(i) Ayse Tolunay Oflu, ${ }^{1}$ (i) Aysegul Bukulmez, ${ }^{1}$ (i) Erdem Icigen, ${ }^{2}$ (i) Lutfi Molon, ${ }^{1}$ (i) Tugba Gursoy Koca, ${ }^{3}$ \\ (D) Yunus Emre Avsar ${ }^{4}$ \\ ${ }^{1}$ Department of Pediatrics, Afyonkarahisar Health Sciences University, Afyonkarahisar, Turkey \\ ${ }^{2}$ Department of Pediatrics, Medical Park Eregli Hospital, Zonguldak, Turkey \\ ${ }^{3}$ Department of Gastroenterology, Pamukkale University Faculty of Medicine, Denizli, Turkey \\ ${ }^{4}$ Department of Child Pyspsychiatry, Eskisehir City Hospital, Eskisehir, Turkey
}

\begin{abstract}
OBJECTIVE: This study aims to investigate the associations between celiac disease (CD) and children's life quality and empathy level.

METHODS: In this study, all participants aged 8-14 years completed the Turkish version of the Pediatric Quality of Life Inventory and Index of Empathy for Children and Adolescents. Parents were also applied to the structured survey.

RESULTS: This study included a study group consisting of 45 children with celiac disease and a control group with 48 healthy children. The total scores of PedsQL were significantly lower for children with celiac disease when compared to the control group $(p<0.05)$. When the sub-scores of PedsQL were evaluated, scores except the school functioning score (ScFS) were significantly lower in the study group $(p<0.05)$. When IECA was analyzed, total empathy scale scores (TESS) were measured significantly higher in the study group $(p<0.05)$.

CONCLUSION: This study supports the argument that the quality of life decreases in children with CD. Future studies should aim to develop support models to improve the life quality of celiac patients. To our knowledge, this is the first study proving the increased empathy levels of children with $\mathrm{CD}$. The determinants of the increased empathy levels should be focussed on future studies.
\end{abstract}

Keywords: Celiac disease; empathy; life quality.

Cite this article as: Oflu AT, Bukulmez A, Icigen E, Molon L, Gursoy Koca T, Avsar YE. Life quality and empathy in children with celiac disease. North Clin Istanb 2020;7(6):557-562.

$\mathrm{C}$ eliac disease (CD) is an immune-mediated, chronic, inflammatory and systemic disorder occurred by the ingestion of gluten, which is a compound of water-insoluble proteins. Wheat, barley, rye, and oats are the sources of gluten $[1,2]$. The diagnosis of celiac disease depends on the gluten-related symptoms, levels of celiac-specific antibodies, presence of HLA-DQ2/DQ8 haplotypes, and characteristic histological changes in duodenal biop- sy [3]. It is presented with various combinations of intestinal and extra-intestinal signs and symptoms in susceptible individuals [2].

Quality of life (QoL) is defined as the perception of individuals about their own position in life in terms of their goals, expectations, standards and concerns within the cultural and value systems [4]. Because of the strict diet, the quality of life of patients with $\mathrm{CD}$ has been a

Received: January 12, 2020 Accepted: June 09, 2020 Online: November 12, 2020

Correspondence: Ayse Tolunay OFLU, MD. Afyonkarahisar Saglik Bilimleri Universitesi, Cocuk Sagligi ve Hastalikları Anabilim Dali, Afyonkarahisar, Turkey.

Tel: +90 5055032929 e-mail: ayseoflu@gmail.com

(c) Copyright 2020 by Istanbul Provincial Directorate of Health - Available online at www.northclinist.com 
matter of curiosity. $\mathrm{CD}$ is a coercive disease requiring lifelong treatment with a strict gluten-free diet (GFD). There are many studies demonstrating reduced $\mathrm{QoL}$ in CD patients both in adults and children [5-7]. It was determined that keeping up GFD has a clear negative effect on the life quality in CD patients since it is very hard to remove such a common nutrient from the diet [8].

Empathy is an experience of understanding other people's feelings and is essential for moral understanding and motivation of favourable behaviour [9]. Empathy is divided into two components: Cognitive empathy and affective empathy [10]. The term 'cognitive empathy' refers to understand other's feelings and the 'affective empathy' is the ability to share emotions [11]. A recent study determined that exposure to individuals with physical disabilities in a family context may facilitate development of positive psychosocial traits, including elevated empathy and compassion in nondisabled siblings. Previous studies on the psychological development of children with a disabled sibling have also shown that those children were characterized by more positive results related to these sibling relationships, such as optimal level of assertiveness, empathy and resilience [12]. While previous studies have been conducted on the empathy level of a child with a disabled sibling, it has not been investigated yet to what extent the empathy levels of children with chronic physical illness vary with their peers. To our knowledge, there is also no study in the literature investigating whether there is a difference between the empathy levels of healthy children and children with celiac disease.

The present study aims to investigate the relations between celiac disease (CD) and children's life quality and empathy level.

\section{MATERIALS AND METHODS}

\section{Study Sample}

Our study was designed as a cross-sectional descriptive study that was conducted between August 04, 2017 and November 01, 2017 in the Afyonkarahisar Health Sciences University Pediatrics clinic. Children aged 8-14 years who were diagnosed either as $\mathrm{CD}$ or healthy were included in this study and informed consent was obtained from all individual participants after the consent of their parents. The sample size was calculated as 39 in group 1 "celiac disease group" and 39 in group 2 "control group" in the $95 \%$ confidence interval using "OpenEpi (https: //www.openepi.com/SampleSize/SSPropor.
Htm) calculator.' The parameters were sustained as Power: $80 \%$, Ratio of sample size (group 1/group 2): 1 , mean \pm SD of group 1 as $14.9 \pm 2.5$ and mean \pm SD of group 2 as $13.1 \pm 3.1$ by a preliminary study.

The diagnosis of CD was based on the criteria set by the European Society for Pediatric Gastroenterology, Hepatology, and Nutrition [13]. All patients with positive serum EMA tests underwent biopsy of the small intestine and all biopsy samples were evaluated according to the modified Marsh criteria. All patients had Type III-c enteropathy according to Marsh's criteria. Children younger than eight years older than 14 years, and patients with any accompanying physical or psychiatric comorbidity and those on GFD for less than six months were excluded from the study. Age and sex-matched Healthy children who did not have any physical or psychiatric disease admitted to paediatric clinics for various reasons were included as controls. All of the controls had a negative serum EMA test.

Ethical approval to conduct this study was obtained from the Afyonkarahisar Health Sciences University's Ethics Committee (No. 04.08.2017/217). All study procedures were performed in accordance with the Declaration of Helsinki.

\section{Data Collection}

The purpose of the study was described and the paper structured surveys, which were self- administered, were given to the parents. Then all participants diagnosed as CD or healthy, completed the Turkish Version of Pediatric Quality of Life Inventory (PedsQL) $[12,13]$ and Index of Empathy for Children and Adolescents (IECA) [14, 15].

\section{PedsQL}

PedsQL is a general tool used to evaluate the children's quality of life and adolescents aged 2-18 [14]. This scale is formed of 23 questions and consists of four subgroups: physical, emotional, social and school functionalities. Emotional functioning score (EFS), social functioning score (SoFS), school functioning score (ScFS), total physical health score (TPhHS), total psychosocial health score (TPsHS), and total scale score (TSS) are measured using Likert-type scoring. Items are scored between 0 and 100 (never $=100$, almost never $=75$, sometimes $=50$, often $=25$, and almost always $=0)$. The higher total score shows better quality of life. The reliability and validity of PedsQL for Turkish children aged 
8-12 and 13-18 were investigated by Cakin Memik et al. [15] and the internal consistency of the scale was 0.86 .

\section{IECA}

ICEA is adapted for children and adolescents by Briant from the Questionnaire Measure of Emotional Empathy $[16,17]$. The validity, reliability and adaptation of the scale for Turkish children were studied by Gürtunca [18] and the internal consistency of the test was calculated as 0.70 . The scale is a 21 -item self-reported paper-pen scale. The lowest score that can be obtained is 0 and the highest score is 21. A higher score reflected more empathy. If the answer is 'yes' the score of item is 1 ; if 'no', the score of the item is 0 . However, some of the items in the scale are reversed. The numbers of the items scored in reverse are $2,8,9,14,15,16,17,19,20$ and 21 .

\section{Statistical Analysis}

Descriptive statistics for the whole sample were generated as follows: Frequency for categorical variables, mean and standard deviation for continuous variables with normal distributions, median with minimum and maximum values for continuous variables without normal distributions. Chi-square test and Fisher's exact test were used to compare the percentage distributions of categorical data between groups. To compare the averages of the groups, the normal distribution of the data was evaluated by the Shapiro Wilk test. In the independent groups, T-test was used to compare when means' distributions were normal. Otherwise, Mann-Whitney U test, Kruskal Wallis test and Spearman's correlation analysis were used to compare. Statistical analysis was performed using the Statistical Package for the Social Sciences (SPSS) 22.0 package program. Values of $\mathrm{p}<0.05$ were considered as statistically significant.

\section{RESULTS}

A total of forty-five patients with celiac disease and 48 healthy children aged between $8-14$ years were included in this study as the study and control groups, respectively. Socio-demographic and clinical characteristics of the study and control groups are given in Table 1 . The mean age of the study group was $11.6 \pm 2.4$ years and 34 (76\%) of them were females. The mean age of the control group was $11.9 \pm 2.1$ years, and $29(60 \%)$ of them were females.

PedsQL and IECA scale scores of the study and control groups are shown in Table 2. When PedsQL scores
TABLE 1. Socio-demographic-clinical characteristics of the study and control groups

\begin{tabular}{|c|c|c|c|}
\hline & $\begin{array}{c}\text { Study } \\
\text { group } \\
(n=45) \\
\%\end{array}$ & $\begin{array}{c}\text { Control } \\
\text { group } \\
(\mathrm{n}=48) \\
\%\end{array}$ & $\mathrm{p}$ \\
\hline Age (years) mean $\pm S D$ & $11.6 \pm 2.4$ & $11.9 \pm 2.1$ & 0.570 \\
\hline Gender (Female) & 76 & 60 & 0.119 \\
\hline Height $(\mathrm{cm})$ mean $\pm S D$ & $141.0 \pm 19.1$ & $153.1 \pm 17.0$ & $0.003^{b}$ \\
\hline Weight $(\mathrm{kg})$ mean $\pm S D$ & $36.5 \pm 13.9$ & $45.8 \pm 15.4$ & $0.003^{b}$ \\
\hline $\mathrm{BMI}\left(\mathrm{kg} / \mathrm{m}^{2}\right)$ mean $\pm \mathrm{SD}$ & $17.4 \pm 3.4$ & $19.0 \pm 3.8$ & $0.036^{a}$ \\
\hline Residence & & & 0.052 \\
\hline City centre & 53.3 & 33.3 & \\
\hline District/Village & 46.7 & 66.7 & \\
\hline Household member & & & 0.160 \\
\hline$\leq 4$ years & 64.4 & 50.0 & \\
\hline$>5$ years & 35.6 & 50.0 & \\
\hline Maternal education level & & & 0.079 \\
\hline Elementary school & 35.6 & 43.8 & \\
\hline Middle school & 35.6 & 45.8 & \\
\hline High school & 128.8 & 10.4 & \\
\hline \multicolumn{4}{|l|}{ Family income } \\
\hline Low & 60.0 & 70.8 & 0.258 \\
\hline Medium/High & 40.0 & 29.2 & \\
\hline \multicolumn{4}{|l|}{ Age at first diagnosis } \\
\hline (years) mean $\pm S D$ & $6.5 \pm 4.5$ & & \\
\hline \multicolumn{4}{|l|}{ Duration of illness } \\
\hline$<2$ years & 46.7 & & \\
\hline $2-5$ years & 42.2 & & \\
\hline$>5$ years & 11.1 & & \\
\hline \multirow{2}{*}{\multicolumn{4}{|c|}{$\begin{array}{l}\text { Adherence to } \\
\text { gluten-free diet }\end{array}$}} \\
\hline & & & \\
\hline Good adherence & 88.9 & & \\
\hline Poor adherence & 11.1 & & \\
\hline \multicolumn{4}{|l|}{ School success } \\
\hline Good & 84.4 & & \\
\hline Bad & 15.6 & & \\
\hline \multicolumn{4}{|l|}{ Relationship with peers } \\
\hline Good & 100 & & \\
\hline Bad & 0 & & \\
\hline
\end{tabular}

SD: Standard deviation; $a: p<0.05 ; \mathrm{b}: \mathrm{p}<0.01$.

were measured, EFS, SoFS, TPhHS, TPsHS and TSS of the study group were significantly lower from the control group ( $p=0.034, p=0.018, p=0.004, p=0.0029$, $p=0.012$, respectively). When IECA was considered, the total empathy scale score (TESS) was measured signif- 
TABLE 2. PedsQL and IECA scores for the study and control groups

\begin{tabular}{lccc} 
& $\begin{array}{c}\text { Study group } \\
(\mathrm{n}=45) \\
\text { Median }\end{array}$ & $\begin{array}{c}\text { Control group } \\
(\mathrm{n}=48) \\
\text { Median }\end{array}$ & $\mathrm{p}$ \\
\hline EFS & 60.0 & 70.0 & $\mathbf{0 . 0 3 4}^{\mathrm{a}}$ \\
SoFS & 80.0 & 90.0 & $\mathbf{0 . 0 1 8}^{\mathrm{a}}$ \\
TPhHS & 65.0 & 75.0 & $\mathbf{0 . 0 0 4}^{\mathrm{b}}$ \\
TPsHS & 67.0 & 75.0 & $\mathbf{0 . 0 2 9}^{\mathrm{a}}$ \\
ScFS & 65.0 & 75.0 & 0.077 \\
TSS & 65.2 & 77.1 & $\mathbf{0 . 0 1 2}^{\mathrm{a}}$ \\
TESS & 15.0 & 14.0 & $\mathbf{0 . 0 0 3}^{\mathrm{b}}$ \\
\hline
\end{tabular}

PedsQL: Quality of Life Inventory; IECA: Index of Empathy for Children and Adolescents; EFS: Emotional functioning score; SoFS: Social functioning score; TPhHS: Total physical healthscore; TPsHS: Total psychosocial health score; ScFS: School functioning score; TSS: Total scalescore; TESS: Total empathy scale score; $a: p<0.05 ; b: p<0.01$.

icantly higher in the study group $(\mathrm{p}=0.003)$. The power analysis of the difference was measured as $86.8 \%$ using 'OpenEpi (https: //www.openepi.com/Power/PowerMean.Htm) calculator'.

Relations of socio-demographic-clinical variables with PedsQL and IECA scores in the study group are given in Table 3. EFS, TPsHS, ScFS and TSS were measured significantly lower among the participants who were unsuccessful at the school $(p=0.003, p=0.035$, $\mathrm{p}=0.008, \mathrm{p}=0.035$, respectively).

\section{DISCUSSION}

In this study, we show that children with CD had a lower quality of life but higher empathy than healthy children. Similarly, QoL of CD patients was lower than healthy children in many previous studies. There is evidence supporting that CD has an effect on patients' QoL and wellbeing. This is probably due to the GFD, which brings difficulties and limitations to the life of the CD patients [19]. Wagner et al. [20] compared the quality of the life of $283 \mathrm{CD}$ and 82 healthy adolescents. They found that patients with bad adherence to GFD had lower scores. On the contrary, there was no difference concerning quality of life between the patients with good adherence to GFD and healthy adolescents. Therefore, researchers concluded that good adherence to GFD in celiac patients is necessary to ensure optimal quality of life. However, our findings do not support this idea because the total and sub-scores of PedsQL were lower for CD patients with good adherence to GFD than the healthy control group. Likewise, we could not find any significant difference between the scores according to the adherence to GFD. Sevinc et al. [7] evaluated and compared the quality of the life levels of $52 \mathrm{CD}$ patients with 40 healthy children. They showed that the quality of the life of patients was lower and they had at least one psychiatric diagnosis. The relationship between patients' quality of life levels and adherence to GFD was examined. It was observed that PedsQL scores were higher in patients with poor dietary compliance, but this difference was not statistically significant. Simsek et al. [21] determined that children who were recently diagnosed as CD had reduced QoL than healthy children. They also found that QoL scores did not change with GFD, but depressive symptom scores significantly decreased. The decrease in QoL scores of CD patients might be related to the burden of this chronic disease requiring a strict diet. It is difficult to say precisely how GFD has effects on QoL scores because of different findings of previous studies. Although the effect of GFD on quality of life is not clear, its effect on reducing depression is more pronounced. Depressive symptoms increase due to the decreased serum tryptophan levels in some celiac patients. It has been shown that GFD for three months increased the serum tryptophan levels and caused a decrease in depressive symptoms $[22,23]$. Even adhering to a GFD promotes recovery of the symptoms; it might not be easy for many patients to adopt such a diet because of poor savour and availability of GFD products. This difficulties cause negative impacts on QoL [24].

Studies have focused on psychiatric symptoms usually described in CD patients, including depression, apathy, excessive anxiety, autism, attention-deficit/hyperactivity disorder, eating and sleep disorders [19]. In this context, to our knowledge, the level of empathy in children with $\mathrm{CD}$ has not yet been investigated in previous studies, and this is the first study to investigate the level of empathy in children with CD. Studies on empathy demonstrate that children with high empathy have better-regulated emotions, less aggression and more positive behaviours [25]. Perenc et al. [12] found that children who have siblings with physical disabilities were more compassionate. They determined that children whose siblings were physically disabled were more empathic than their peers. They suggested that chronic stress caused with the presence of a disabled sibling in the family might have positive psychosocial effects such as increased empathy 


\begin{tabular}{|c|c|c|c|c|c|c|c|}
\hline & EFS & SoFS & TPhHS & TPsHS & ScFS & TSS & TESS \\
\hline \multicolumn{8}{|l|}{ Gender } \\
\hline Female $(n=34)$ & $60.0 * *$ & 70.0 & 64.0 & 64.5 & 67.5 & 65.2 & 15.0 \\
\hline Male $(n=11)$ & 65.0 & 85.0 & 65.0 & 79.0 & 65.0 & 71.7 & 15.0 \\
\hline $\mathrm{p}$ & 0.611 & 0.649 & 0.441 & 0.999 & 0.506 & 0.845 & 0.382 \\
\hline \multicolumn{8}{|l|}{ Family income } \\
\hline Low $(n=27)$ & 60.0 & 65.0 & 65.0 & 53.0 & 65.0 & 73.8 & 15.0 \\
\hline Medium/High $(n=18)$ & 62.5 & 82.5 & 67.5 & 70.0 & 70.0 & 65.1 & 15.0 \\
\hline $\mathrm{p}$ & 0.795 & 0.392 & 0.688 & 0.273 & 0.670 & 0.851 & 0.805 \\
\hline \multicolumn{8}{|l|}{ Maternal education level } \\
\hline Elementary school $(n=16)$ & 57.5 & 72.5 & 63.5 & 60.0 & 62.5 & 65.1 & 14.0 \\
\hline Middle school $(n=16)$ & 57.5 & 70.0 & 59.5 & 63.5 & 65.0 & 63.5 & 15.0 \\
\hline High school $(n=13)$ & 65.0 & 90.0 & 78.0 & 73.0 & 75.0 & 73.0 & 16.0 \\
\hline $\mathrm{p}$ & 0.608 & 0.807 & 0.253 & 0.828 & 0.554 & 0.528 & 0.422 \\
\hline \multicolumn{8}{|l|}{ School success } \\
\hline Good $(n=38)$ & 65.0 & 85.0 & 70.5 & 74.0 & 70.0 & 73.8 & 15.0 \\
\hline $\operatorname{Bad}(n=7)$ & 50.0 & 60.0 & 53.0 & 50.0 & 50.0 & 50.0 & 15.0 \\
\hline $\mathrm{p}$ & $0.003^{b}$ & 0.123 & 0.221 & $0.035^{\mathrm{a}}$ & $0.008^{b}$ & $0.035^{\mathrm{a}}$ & 0.433 \\
\hline \multicolumn{8}{|l|}{ Adherence to gluten-free diet** } \\
\hline Good adherence $(n=40)$ & 60.0 & 80.0 & 64.0 & 64.5 & 65.0 & 68.4 & 15.0 \\
\hline Poor adherence $(n=5)$ & 65.0 & 65.0 & 72.0 & 67.0 & 70.0 & 65.0 & 15.0 \\
\hline $\mathrm{p}$ & 0.539 & 0.903 & 0.493 & 0.586 & 0.539 & 0.562 & 0.739 \\
\hline \multicolumn{8}{|l|}{ Duration of illness } \\
\hline$<2$ years $(n=21)$ & 60.0 & 65.0 & 63.0 & 62.0 & 70.0 & 65.0 & 15.0 \\
\hline $2-5$ year $(n=19$ & 65.0 & 90.0 & 75.0 & 79.0 & 70.0 & 77.1 & 15.0 \\
\hline$>5$ years $(n=5)$ & 60.0 & 85.0 & 60.0 & 60.0 & 60.0 & 60.0 & 15.0 \\
\hline $\mathrm{p}$ & 0.949 & 0.428 & 0.494 & 0.530 & 0.772 & 0.244 & 0.827 \\
\hline \multicolumn{8}{|l|}{ Age at the first diagnosis*** } \\
\hline$r$ & 0.089 & 0.049 & 0.263 & 0.076 & 0.159 & 0.163 & -0.113 \\
\hline $\mathrm{p}$ & 0.559 & 0.749 & 0.081 & 0.620 & 0.297 & 0.284 & 0.462 \\
\hline
\end{tabular}

EFS: Emotional functioning score; SoFS: Social functioning score; TPhHS: Total physical health score; TPsHS: Total psychosocial health score; ScFS: School functioning score; TSS: Total scale score; TESS: Total empathy scale score; *: Mann-Whitney U test, Kruskal Wallis test and Spearman's correlation analysis were used to compare; **: Median values; ***: Good adherence to diet.

of a child [26]. We also found that $\mathrm{CD}$, which requires lifelong diet therapy, increases the level of empathy in children. We think that chronic stress in children with CD increases the level of empathy and compassion. Empathy is also very important for children to contact their friends [12]. We determined that all of the children with CD get along well with their friends.

There are some limitations in our study. First, this was a cross-sectional study, so the results may be affected by instant situations and any outcome related to causality are not possible to allege. Second, it was a self-reporting survey and scale study, so this study may have a risk of perfunctory, concealment and short-term memory biases. Third, our sample size is not big enough to make a generalization of the results.

\section{Conclusions}

In this study, we concluded that QoL decreases and empathy level increases in children with CD. Either impaired quality of life and increased level of empathy was not related to gender, adherence to GFD, duration of illness and age at the first diagnosis. Further prospective studies 
with larger sample size are needed to investigate the factors that affect the QoL of celiac patients negatively. To our knowledge, this is the first study focusing on the empathy of children with CD. It is a new question if empathy is also high in children with other chronic childhood disease or if it is specific condition for only celiac patients. The reasons of increased empathy in celiac patients are a new research topic for the future prospective studies.

Acknowledgements: The authors thank the all participants.

Ethics Committee Approval: Afyonkarahisar Health Sciences University Clinical Research Ethics Committee granted approval for this study (date: 04.08.2017, number: 217/8).

Conflict of Interest: No conflict of interest was declared by the authors.

Financial Disclosure: The authors declared that this study has received no financial support.

Authorship Contributions: Concept - ATO, AB; Design - TO, AB, TGK; Supervision - ATO, AB, YEA; Materials - ATO, EI, LM, TGK, YEA; Data collection and/or processing - ATO, EI, LM, TGK, YEA; Analysis and/or interpretation - $A T O, A B$, $L M$; Literature review ATO, AB, EI, LM, TGK, YEA; Writing - ATO, AB, EI, LM, TGK, YEA; Critical review - ATO, AB.

\section{REFERENCES}

1. Rubio-Tapia A, Hill ID, Kelly CP, Calderwood AH, Murray JA; American College of Gastroenterology. ACG clinical guidelines: diagnosis and management of celiac disease. Am J Gastroenterol 2013;108:65676. [CrossRef]

2. Moreno ML, Rodríguez-Herrera A, Sousa C, Comino I. Biomarkers to Monitor Gluten-Free Diet Compliance in Celiac Patients. Nutrients 2017;9:46. [CrossRef]

3. Husby S, Koletzko S, Korponay-Szabó IR, Mearin ML, Phillips A, Shamir R, et al; ESPGHAN Working Group on Coeliac Disease Diagnosis; ESPGHAN Gastroenterology Committee; European Society for Pediatric Gastroenterology, Hepatology, and Nutrition. European Society for Pediatric Gastroenterology, Hepatology, and Nutrition guidelines for the diagnosis of coeliac disease. J Pediatr Gastroenterol Nutr 2012;54:136-60. [CrossRef]

4. Study protocol for the World Health Organization project to develop a Quality of Life assessment instrument (WHOQOL). Qual Life Res 1993;2:153-9. [CrossRef]

5. Norström F, Lindholm L, Sandström O, Nordyke K, Ivarsson A. Delay to celiac disease diagnosis and its implications for health-related quality of life. BMC Gastroenterol 2011;11:118. [CrossRef]

6. de Lorenzo CM, Xikota JC, Wayhs MC, Nassar SM, de Souza Pires MM. Evaluation of the quality of life of children with celiac disease and their parents: a case-control study. Qual Life Res 2012;21:77-85.

7. Sevinç E, Çetin FH, Coşkun BD. Psychopathology, quality of life, and related factors in children with celiac disease. J Pediatr (Rio J) 2017;93:267-73. [CrossRef]

8. Bernardo D, Peña AS. Developing strategies to improve the quality of life of patients with gluten intolerance in patients with and without coeliac disease. Eur J Intern Med 2012;23:6-8. [CrossRef]

9. Eisenberg N, Cumberland A, Guthrie IK, Murphy BC, Shepard SA. Age Changes in Prosocial Responding and Moral Reasoning in Adolescence and Early Adulthood. J Res Adolesc 2005;15:235-60. [CrossRef]

10. Gruen RJ, Mendelsohn G. Emotional responses to affective displays in others: The distinction between empathy and sympathy. Journal of Personality and Social Psychology 1986;51:609-14. [CrossRef]

11. Stuijfzand S, De Wied M, Kempes M, Van de Graaff J, Branje S, Meeus W. Gender Differences in Empathic Sadness towards Persons of the Same- versus Other-sex during Adolescence. Sex Roles 2016;75:43446. [CrossRef]

12. Perenc L, Pęczkowski R. Cognitive and affective empathy among adolescent siblings of children with a physical disability. Disabil Health J 2018;11:43-8. [CrossRef]

13. Hill ID, Dirks MH, Liptak GS, Colletti RB, Fasano A, Guandalini S, et al; North American Society for Pediatric Gastroenterology, Hepatology and Nutrition. Guideline for the diagnosis and treatment of celiac disease in children: recommendations of the North American Society for Pediatric Gastroenterology, Hepatology and Nutrition. J Pediatr Gastroenterol Nutr 2005;40:1-19. [CrossRef]

14. Varni JW, Seid M, Rode CA. The PedsQL: measurement model for the pediatric quality of life inventory. Med Care 1999;37:126-39. [CrossRef]

15. Cakin Memik N, Ağaoğlu B, Coşkun A, Uneri OS, Karakaya I. The validity and reliability of the Turkish Pediatric Quality of Life Inventory for children 13-18 years old. Turk Psikiyatri Derg 2007;18:353-63.

16. Bryant BK. An index of empathy for children and adolescents. Child Dev 1982;53:413-25. [CrossRef]

17. Mehrabian A, Epstein N. A measure of emotional empathy. J Pers 1972;40:525-43. [CrossRef]

18. Gürtunca A. An index of empathy for children and adolescents Turkey reliability and validity work. [Thesis]. Istanbul: Arel University; 2013. Available at: https://toad.halileksi.net/sites/default/files/pdf/cocuklar-ve-ergenler-icin-empati-olcegi-toad.pdf. Accessed Oct 13, 2020

19. Campagna G, Pesce M, Tatangelo R, Rizzuto A, La Fratta I, Grilli A. The progression of coeliac disease: its neurological and psychiatric implications. Nutr Res Rev 2017;30:25-35. [CrossRef]

20. Wagner G, Berger G, Sinnreich U, Grylli V, Schober E, Huber WD, et al. Quality of life in adolescents with treated coeliac disease: influence of compliance and age at diagnosis. J Pediatr Gastroenterol Nutr 2008;47:555-61. [CrossRef]

21. Simsek S, Baysoy G, Gencoglan S, Uluca U. Effects of Gluten-Free Diet on Quality of Life and Depression in Children With Celiac Disease. J Pediatr Gastroenterol Nutr 2015;61:303-6. [CrossRef]

22. Hernanz A, Polanco I. Plasma precursor amino acids of central nervous system monoamines in children with coeliac disease. Gut 1991;32:1478-81. [CrossRef]

23. Pynnönen PA, Isometsä ET, Verkasalo MA, Kähkönen SA, Sipilä I, Savilahti E, et al. Gluten-free diet may alleviate depressive and behavioural symptoms in adolescents with coeliac disease: a prospective follow-up case-series study. BMC Psychiatry 2005;5:14. [CrossRef]

24. Khoshbaten M, Rostami Nejad M, Sharifi N, Fakhari A, Golamnejad $\mathrm{M}, \mathrm{Hashemi} \mathrm{SH}$, et al. Celiac disease in patients with chronic psychiatric disorders. Gastroenterol Hepatol Bed Bench 2012;5:90-3.

25. Eisenberg N. Emotion, regulation, and moral development. Annu Rev Psychol 2000;51:665-97. [CrossRef]

26. Allemand M, Steiger AE, Fend HA. Empathy development in adolescence predicts social competencies in adulthood. J Pers 2015;83:22941. [CrossRef] 